\title{
CHEMICAL EVIDENCE OF HYDROGEN SORPTION PROCESSES ON POTENTIAL CYCLED GOLD ELECTRODES
}

\author{
M. E. Martins, J. J. Podestá and A. J. Arvia
}

Instituto de Investigaciones Fisicoquimicas Teóricas y Aplicadas (INIFTA), Fucultad de Ciencias Exactas, Universidad Nacional de La Plata, Casilla de Correo 16, Sucursal 4, 1900 La Plata, Argentina

(Received 12 August 1986; in revised form 18 November 1986)

\begin{abstract}
Transient activation of polycrystalline gold electrodes for the hydrogen clectrode reaction, produced either through potentiostatic or potentiodynamic treatment, is related to the adsorption of $H$ atoms and its penetration into the bulk. Evidence for $\mathbf{H}$ atoms results from the application of silver crystal decoration lechnique. Hydrogen-loaded activated gold electrodes in contact with a soluble silver salt solution yield silver deposits which can be studied through conventional voltammetric stripping. Ihe increase in activation for the HER correlates with the increase in the voltammetric contribution of 0 electroadsorption peak assigned to the (110) crystallographic face of gold. The development of a faceled surface structure with preferred orientation in the direction of the less dense atomic arrangement apparently favours the penetration of hydrogen into the bulk metal.
\end{abstract}

\section{INTRODUCTION}

Under conditions of intense evolution of hydrogen on polycrystalline gold electrodes in acid solutions, the diffusion of hydrogen presumably as atomic hydrogen into the bulk of the metal is favoured. In this case gold electrodes result with a particular transient activation for the hydrogen evolution reaction (HER) which is probably related to hydrogen both adsorption and absorption processes [1-4]. This type of activation can be substantially enhanced by means of potentiodynamic cycles covering a certain potential range where 0 eloctroadsorption-electrodesorption on gold in acid takes place $[5,6]$. The process is accompanied by the ageing of the 0 electroadsorbed species which is reflocted through the increase in the overvoltage for 0 adatom electroreduction and it implies a relatively small change in surface roughness as followed through the electrodesorption charge for 0 adatoms. The entire process at the end also leads to the development of crystallographic faceting $[7,8]$.

The present work attempts to demonstrate the existence of different hydrogen species on activated gold by means of chemical techniques particularly useful to follow the microstructural distribution of hydrogen near a metal surface or at exit point of the hydrogen flux out from the metal[9, 10]. For the present case silver crystal decoration was principally used. The amount of deposited silver can be followed voltammetrically or its location on the surface imaged through scanning electron microscopy.

\section{EXPERIMENTAL}

Working electrode $\left(0.071 \mathrm{~cm}^{2}\right.$ apparent area) consisted of disc surfaces made of a polycrystalline gold (spectroscopic quality) rod axially embedded in a PTFE rod. Each gold electrode was mechanically polished with alumina powder-water suspension $(5,1$ and $0.3 \mu \mathrm{m}$ ). The counterelectrode was a spiral gold wire $\left\{0.05 \mathrm{~cm}\right.$ dia., $c a 10 \mathrm{~cm}^{2}$ apparent area) adequately shielded to prevent diffusion of reaction products to the working electrode compartment. A platinum-hydrogen electrode properly shielded was used as reference. Runs were made in $1 \mathrm{M} \mathrm{H}_{2} \mathrm{SO}_{4}$ prepared from MilliQ water and a.r. $98 \% \mathrm{H}_{2} \mathrm{SO}_{4}$ (Merck). Experiments were performed under purified nitrogen without solution stirring at $20 \pm 1^{\circ} \mathrm{C}$. Each run involves three main stages, namely, the activation of gold electrode, the electrowemical hydrogen loading and the detection and evaluation of electrochemically loaded hydrogen.

The activation stage was applied to an electrode which was previously potential scanned between $\boldsymbol{E}_{s, c}$ $=0 \mathrm{~V}$ and $E_{\mathrm{s} \text { a }}=1.76 \mathrm{~V}$ at $v=0.2 \mathrm{~V} \mathrm{~s}^{-1}$ to obtain the corresponding stabilized voltammogram. The activation stage consisted of a repetitive triangular potential cycling within the 0 electrosorption electrodesorp. tion potential region, namely between $E_{\text {s. }}^{\prime}=1.17 \mathrm{~V}$ and $E_{\text {s. } a}=1.76 \mathrm{~V}$, at $v=0.2 \mathrm{Vs}^{-1}$ during the time $\tau$ $(15 s<\tau<1 \mathrm{~h})$. The electroshemical hydrogen loading was made by changing $E_{s, 1}^{\prime}$ to $E_{s, d}=-0.23 \mathrm{~V}$ during time $\tau^{\prime}$. Finally, for the detection and evaluation of local hydrogen, the eloctrode was removed from the cell, washed with MilliQ water, and immersed in either $2.8 \times 10^{5} \mathrm{M}$ or $4.6 \times 10^{4} \mathrm{M}\left[\mathrm{Ag}(\mathrm{CN})_{2}\right] \mathrm{K}$ during a certain time $\tau^{\prime \prime}$. The silver pattern developed on the gold electrode surface was removed through anodic stripping in $1 \mathrm{M} \mathrm{H}_{2} \mathrm{SO}_{4}$ starting from $E_{s, c}=$ $-0.23 \mathrm{~V}$ to $E_{s, 0}=1.78 \mathrm{~V}$. Oocasionally nickel patterns obtained through acid nickel electrodeposition was also used as test reaction [11].

Blank experiments were systematically made to compare the behaviour of both non-activated and activated gold electrodes. The test reactions on conventional gold surfaces were negative as no active hydrogen was available[12]. Inspection of the decorated surfaces previously to stripping was carried out by SEM. 


\section{RESULTS}

Comparative voltammetry of activated and nonactivated gold electrodes in $1 \mathrm{M} \mathrm{H}_{2} \mathrm{SO}_{4}$

The voltammogram of a non-activated pc gold electrode in $1 \mathrm{M} \mathrm{H}_{2} \mathrm{SO}_{4}$ run at $0.2 \mathrm{~V} \mathrm{~s}^{-1}$ between $-0.25 \mathrm{~V}$ and $1.78 \mathrm{~V}$ (Fig. 1) presents three well-defined regions associated with the 0 electroadsorption-electrodesorption (region I) $(1.0-1.78 \mathrm{~V})$, the electrical double layer charging-discharging (region $\mathrm{H})(0-1.0 \mathrm{~V})$ and the HER (region III) $(E<0 \mathrm{~V})$. Otherwise, the voltammogram resulting for an electrode previously activated under the following conditions, $E_{s, a}$ $=1.78 \mathrm{~V}, E_{s . c}^{\prime}=1.16 \mathrm{~V}, v=0.2 \mathrm{Vs}^{-1}$ and $t=30 \mathrm{~min}$ (Fig. 1) exhibits substantial differences in regions I, II and III. For activated electrodes, region I shows a change in the charge distribution for the 0 electroadsorption, the charge enhancement for the anodic peak located at lower potentials, the slight increase in the overall charge for 0 electrosorption and the shift of the potential for the 0 electrodesorption peak towards more negative values. Region II exhibits a net cathodic current plateau, probably related to the electrodeposition of soluble gold species produced during the activation treatment. Correspondingly, the HER current is considerably increased and a complementary anodic current contribution is recorded. Voltammetric changes in region I are assigned to the development of a certain electrochemical faceting of the gold surface with preferred crystallographic orientation, whereas those in region III reveal the particular activation for the HER.

Anodic stripping of silver from activated gold and from gold previously cathodized in region $\mathrm{I}$

Activated gold electrodes which were immersed in the silver ion containing solution during a certain time $\tau^{\prime \prime}$, exhibit the already known silver stripping voltammograms (Fig. 2). Thus, the first anodic scan in $1 \mathrm{M}$ $\mathrm{H}_{2} \mathrm{SO}_{4}$ shows an anodic peak corresponding to bulk silver stripping at $0.74 \mathrm{~V}$, followed by a second peak at $0.8 \mathrm{~V}$, whereas the subsequent cathodic scan presents a complex cathodic current peak at $0.68 \mathrm{~V}$ which corresponds to the complementary silver electrodeposition reaction. On extending the stripping voltam- mogram to $1.83 \mathrm{~V}$, a second small stripping peak is recorded at $c a 1.18 \mathrm{~V}$, followed by the 0 electroadsorption-electrodesorption reaction current. Repetitive silver anodic stripping cycles run between $-0.25 \mathrm{~V}$ and $1.78 \mathrm{~V}$ reveal the formation of two layers (Fig. 3). Thus, as the number of stripping cycles increases, firstly the main peak at $0.69 \mathrm{~V}$ and later those corresponding to upd silver disappear. Similar results were obtained by holding the gold electrode at $E=$ $-0.25 \mathrm{~V}$ for at least $30 \mathrm{~min}$. In this case longer times are required to obtain effects comparable to those resulting through RTPS treatment. The silver stripping voltammogram coincides with that recorded for pc gold in $x$ M Ag $2 S_{4}\left(10^{-5}<x<10^{3}\right)+1 \mathrm{M}$ $\mathrm{H}_{2} \mathrm{SO}_{4}$ solution (Fig. 4) [13, 14].

The greatest efficiency for activation of gold for HER through the TRPS treatment is achieved for $E_{s . c}^{\prime}$ $=1.16 \mathrm{~V}$, in agreement with earlier results [6]. Furthermore, by plotting $Q_{s}$, the charge related to the stripped silver, as a function of $\tau$ (Fig. 5) after $300 \mathrm{~s} \mathrm{a}$ limiting efficiency in silver deposition is attained. Similarly, regarding $t^{\prime \prime}$, the time during which the hydrogen loaded gold electrode is immersed in the silver salt solution, at $c a 250 \mathrm{~s}$ the efficiency attains a constant value (Fig. 5).

\section{SEM and EDAX data}

The SEM micrographs of activated gold electrodes after immersion in the silver salt solution (Fig. 6) exhibit regions with an apparently random distribution of silver dendrites and others, appearing as nearly circular patches where no silver deposits can be distinguished at the magnification level of these experiments. EDAX data confirms the silver growing dendrites.

\section{DISCUSSION}

The potentiodynamic activation of gold in $1 \mathrm{M}$ $\mathrm{H}_{2} \mathrm{SO}_{4}$ produces an enhancement of the electrocatalytic activity of the hydrogen evolution reaction, and simultaneously, a change in the 0 adatom electrosorption profile in the dircction of developing a relatively open crystallographic structure, probably related to

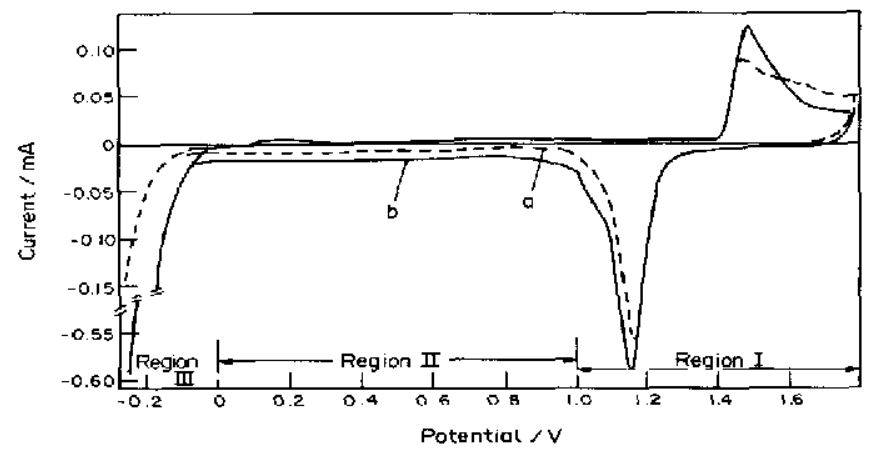

Fig. 1. Potentiodynamic $E / I$ profiles at $0.2 \mathrm{Vs}^{-1} ; \mathrm{Au} / 1 \mathrm{M} \mathrm{H}_{2} \mathrm{SO}_{4}, 20^{\circ} \mathrm{C},(---) \mathrm{RTPS}$ stabilized voltammogram; ( - ) TPS voltammogram run after potentiodynamic ageing at $0.2 \mathrm{~V} \mathrm{~s}^{-1} ; E_{s, c}^{\prime}=1.16 \mathrm{~V} ; \tau$ $=30 \mathrm{~min}$. 


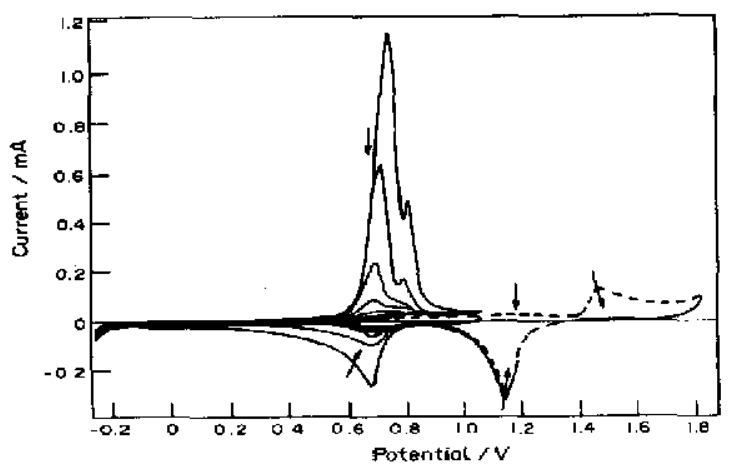

Fig. 2. RTPS voltammograms of activated gold electrode run at $0.2 \mathrm{~V} \mathrm{~s}^{-1}$ after immersion in the silver salit solution, $E_{s, c}=$ $-0.25 \mathrm{~V},\left(\longrightarrow E_{3, a}=1.07 \mathrm{~V} ;(--) E_{a, a}=1.83 \mathrm{~V}\right.$. 1 $\mathrm{M} \mathrm{H} \mathrm{SO}_{4}, 20^{\circ} \mathrm{C}$.

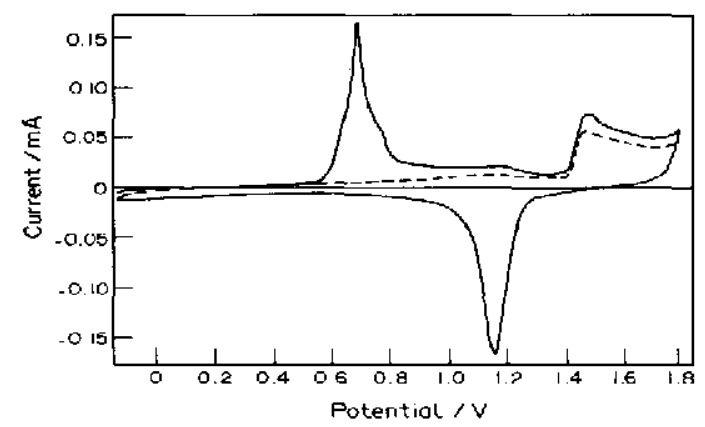

Fig. 3. RTPS voltammograms run at $0.2 \mathrm{Vs}^{-1}$ of activated gold electrode after immersion in the silver salt solution, $E_{s, c}$ $=-0.14 \mathrm{~V} ; E_{s, a}=1.79 \mathrm{~V} ;(-)$ first cycle; $(--)$ second cycle; $1 \mathrm{M} \mathrm{H}_{2} \mathrm{SO}_{4}, 20^{\circ} \mathrm{C}$.

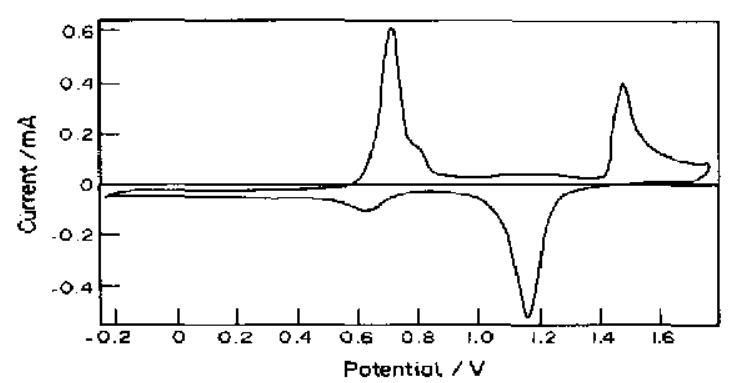

Fig. 4. Stabilized voltammogram run at $0.2 \mathrm{Vs}^{-\mathrm{t}}$; $\mathrm{Au} / \mathrm{l}$ $\mathrm{M} \mathrm{H}_{2} \mathrm{SO}_{4}+8.8 \times 10^{-4} \mathrm{M} \mathrm{Ag}_{2} \mathrm{SO}_{4}, 20^{\circ} \mathrm{C}$.

the predominance of a (110)-type faceting, as revealed by the increase in height of the 0 electroadsorption peak at $c a 1.48 \mathrm{~V}$, in the voltammogram corresponding to the activated electrode [8]. This change occurs with a relatively small change in electrode roughness, at least

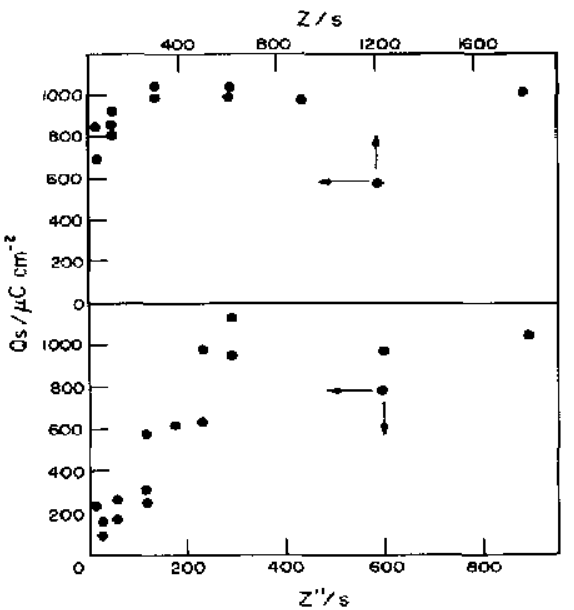

Fig- 5. $Q$, vs $\tau$ (upper) and $\tau^{\prime \prime}$ (lower) plots.

for the 0 adatom electroadsorption-electrodesorption reaction.

The amount of local hydrogen is proportional to the stripping charge for silver. The formation of silver on the surface of activated gold electrodes loaded with hydrogen corresponds to a displacement reaction which can be written as the following overall reactions:

$$
\begin{aligned}
& \mathrm{Ag}^{+}(\mathrm{aq})+\mathrm{H}_{i}^{*}=\mathrm{Ag}(\mathrm{upd})+\mathrm{H}^{+}(\mathrm{aq}) \\
& \mathrm{Ag}^{+}(\mathrm{aq})+(\mathbf{H})^{*}=\mathrm{Ag}(3 \mathrm{D})+\mathrm{H}^{+}(\mathrm{aq})
\end{aligned}
$$

where $\mathrm{Ag}^{+}$results from the dissociation of the dicyano-silver complex ion:

$$
\left[\mathrm{Ag}(\mathrm{CN})_{2}\right]^{-}(\mathrm{aq})=\mathrm{Ag}^{+}(\mathrm{aq})+2 \mathrm{CN}^{-}(\mathrm{aq})
$$

and $(H)_{i}^{*}$ represents an active form of hydrogen at the surface, whose nature can be inferred through the anodic stripping voltammograms themselves. The equilibrium constant of reaction $(2)$, at $25^{\circ} \mathrm{C}$, is $10^{-21.1}[15]$. Reaction (1) must occur only at the activated gold surface, as it is known that atomic hydrogen practically does not exist on gold. Nevertheless, the voltammetric data indicate that the amount of silver stripped out can exceed by a large amount the charge corresponding to a monolayer of atoms. In addition, stripping voltammetry shows that both bulk (3D) silver and upd silver exist on the electrode surface. Therefore, one must admit that hydrogen penetration into the metal has occurred up to a certain depth, according to the degree of activation of the electrode and the duration of holding the potential at $E_{s, c}$. In this case, for the reaction of $(H)_{i}^{*}$ and $\mathrm{Ag}^{+}$to occur, the displacement of $(\mathrm{H})_{i}^{*}$ from the bulk of the metal to the clectrochemical interface should be required. Accordingly, reaction (1) should imply a transport of underneath active hydrogen $(\mathrm{H})_{*}^{*}$ to the metal surface $(\mathbf{H})_{i}^{*}$, which can be represented as follows:

$$
(\mathrm{H})_{i}^{*} \rightarrow(\mathbf{H})_{i}^{*} \text {. }
$$

There is evidence reported in literature[2] that such a process actually occurs through thin gold electrodes. 

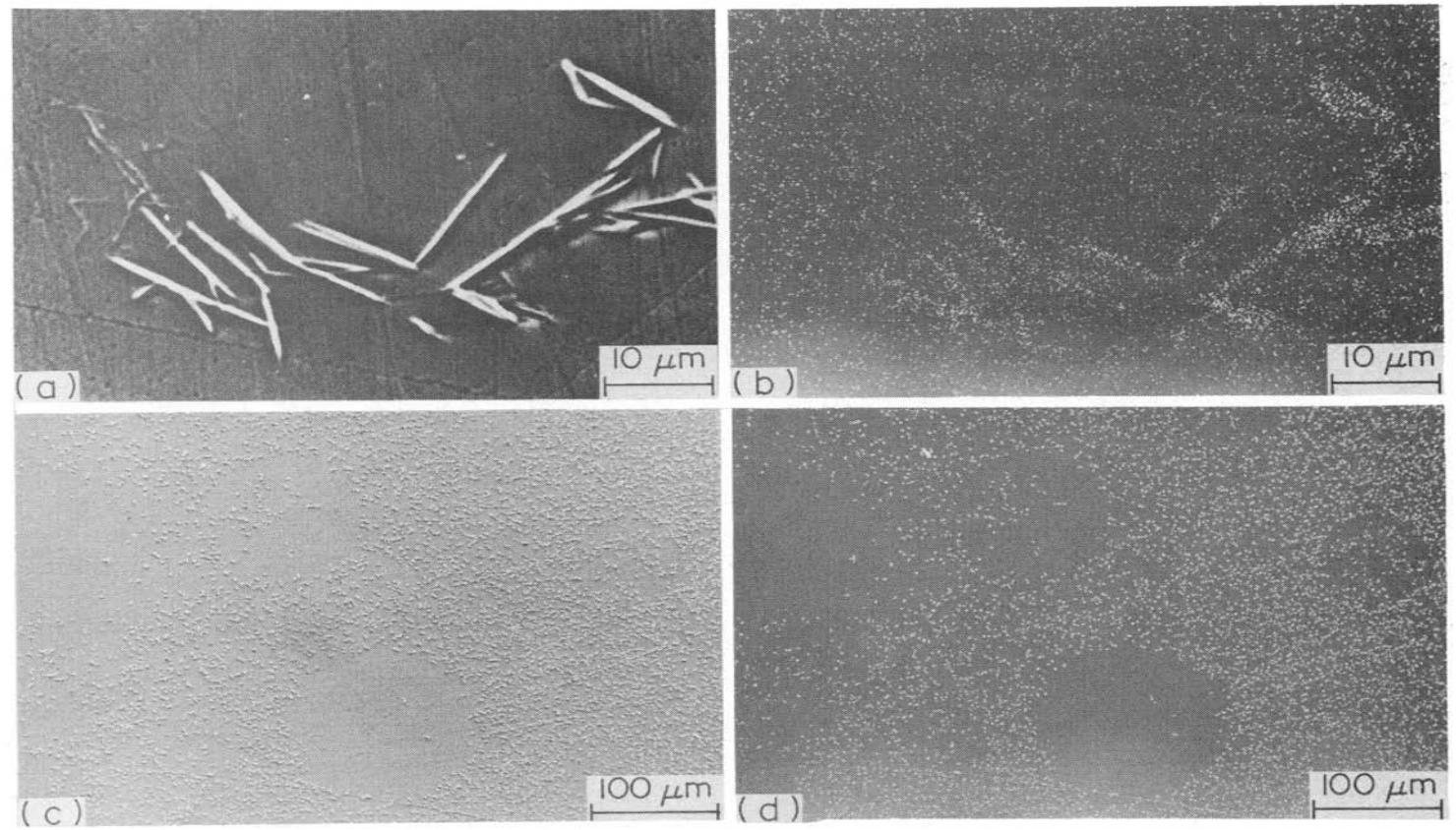

Fig. 6. SEM (a, c) and EDAX (b, d) micrographs of activated gold elcetrode after immersion in the silver salt solution $2.8 \times 10^{-9} \mathrm{M}$. (a) and (b) $\tau=10 \mathrm{~min} ; \tau^{\prime \prime}=10 \mathrm{~min}$. (c) and (d) $t=10 \mathrm{~min}$; $\tau^{\prime \prime}=20 \mathrm{~min}$.

It should be noticed that reaction (3) becomes presumably more complex because of the participation of equilibria involving molecular hydrogen and both kinds of atomic hydrogen. Otherwise, reaction (1) occurring at the active gold surface layer also should imply a diffusion of silver atoms to sites yielding 3D nuclei growth. This means that 3D silver growth process represented by reaction (1) presumably operates under a diffusion control. In this case one should tentatively consider that the rate of reaction (1b) itself is controlled by either the transport of $\mathrm{Ag}^{+}$ions from solution or surface diffusion of adatoms to nucleation sites and growing borders. In this respect silver electrocrystallization data involves the mobility of $\mathbf{A g}$ adatoms so that the overall 3D growing effect probably corresponds to a consortial action involving the surface diffusion of $\mathrm{Ag}$ adatom, and mass transport of $\mathrm{Ag}^{+}$ion from solution.

According to the voltammetric response of activated gold [6] there is a local equilibrium between $(\mathbf{H})_{u}^{*},(\mathbf{H})_{i}^{*}$ and $\mathrm{H}^{+}$, namely:

$$
\begin{aligned}
& (\mathbf{H})_{w}^{*}=(\mathbf{H})_{i}^{*}=\mathbf{H}^{+}+\mathbf{e}^{-} \\
& \text {iv } \\
& 1 / 2 \mathrm{H}_{2} \text {. }
\end{aligned}
$$

This reaction can explain the transient activation for the hydrogen electrode reaction on activated gold in acid. The relationship between absorbed and adsorbed hydrogen at equilibrium, should presumably obey Sievert's equation, as it has been observed for other metals [9]. In this case, the degree of surface coverage of gold $\left(\theta_{\mathrm{H}^{*}}\right)$ for $(\mathrm{H})_{i}^{*}$ should be principally related to the $\mathbf{H}-\Lambda \mathrm{u}$ bond strength. For very low energy sites,
$\left(\theta_{\mathrm{H}^{*}}\right) \rightarrow 0$ and neither $\mathrm{H}$ adsorption nor $\mathrm{H}$ absorption are favoured. But for activated gold, the (H-Au)* bond strength at activated sites, should be greater than the $\mathrm{H}$-Au bond strength in non-active sites, providing that the surface density of Au states is greater than for Au* states. This means that the $H$ atom discharge step, in principle, can be followed by a diffusion of $\mathrm{H}$ atom from $\mathrm{Au}$ to $\mathrm{Au}^{*}$ sites, that is:

$$
\begin{gathered}
\mathbf{H}^{+}+\mathrm{Au}\left(e^{-}\right)=\mathbf{A u}(\mathbf{H}) \\
\mathrm{Au}(\mathbf{H})+\mathbf{A u}^{*}=(\mathrm{Au}-\mathbf{H})^{*}+\mathrm{Au} .
\end{gathered}
$$

The increase in the (H-Au)* bond encrgy increases the discharge rate, slows down any $\mathrm{H}$ adatom combination and increases $\mathbf{H}$ absorption. Then,

$$
A u^{*}(\mathbf{H})=(\mathbf{H})+\mathrm{Au}^{*} \text {. }
$$

These processes can be described in terms of conventional potential energy diagrams, on the assumption that the distance of the (H-Au)* bond is shorter than that for the $\mathrm{H}-\mathrm{Au}$ bond. Therefore, a situation arises where the $\mathrm{H}$ absorption desorption from $\mathrm{Au}^{*}$ sites is favoured as compared to $\mathrm{Au}$ sites since the free energy of activation related to $\mathrm{Au}^{*}$ sites becomes smaller than that corresponding to Au sites for the processes in both directions.

On the basis that the (110)-type preferred orientation is enhanced during the activation treatment [8], for the activated gold surface consisting of a mixture of $\mathrm{Au}$ and $\mathrm{Au}^{*}$ sites, it seems reasonable to expect that $\mathrm{Au}^{*}$ be located at the faceted positions of the surface. Therefore, the concentration of $\mathrm{H}$ atoms either at these regions or defects in the faceted regions should be greater than in the rest of the surface which comprises 
less dense packed crystallographic faces. Therefore, they can be assigned to Au" centers for active hydrogen inlet to and outlet from the bulk metal. The same line of reasoning can be extended to defects at the crystallographic surface of polycrystalline gold promoted during the activation procedure. SEM micrographs reveal that silver nucleation and growth caused by hydrogen loaded active gold electrodes is non-uniform and, depending on the amount of loaded hydrogen, silver dendrites structures, can be accomplished.

Finally, the chemical tests made with activated gold electrodes for the hydrogen electrode reaction confirm the conclusion of previous works exclusively based on electrochemical measurements $[1-8]$.

Acknowledgements - This work was financially supported by the Universidad Nacional de La Plata, the Consejo Nacional de Investigaciones Científicas y Técnicas and the Comisión de Investigaciones Cientificas de la Provincia de Buenos Aires.

\section{REFERENCES}

1. F. Chao and M. Costa, C.r. Acad. Sci. Paris 284, Série C, $603(1977)$.
2. F. Chao, M. Costa and P. Elkaim, C.r. Acad. Sci. Paris 284, Série C, 639 (1977).

3. F. Chao and M. Costa, C.r. Acad. Sci. Paris 284, Série C, 763 (1977).

4. F. Chao, M. Costa, R. Parsons and C. Grattepain, $J$. electroanal. Chem. 115, 31 (1980).

5. R. Córdova O., M. E. Marting and A. I. Arvia, Electrochim. Acta 24, 469 (1979).

6. R. Córdova O., M. E. Martins and A. J. Arvia, $J$ electrochem. Soc. 127, 2628 (1980).

7. M. C. Galindo, M. E. Martins and A. J. Arvia, An Asoc. Quím. Arg. 74, 215 (1986).

8. C. L. Perdriel, M. Ipohorski and A. J. Arvia, J. electroanal. Chem. 215, 317 (1986).

9. P. L. Subramanyan, in Comprehensite Treatse of Electochemisty (Edited by J. O'M. Bockris, B. Conway, E. Yeager and R. White), Vol. 4, p. 411. Plenum Press, New York (1981).

10. T. Schober and C. Dieker, Metall. Trans. 14A, 2440 (1983).

11. C. E. Yamashiro, J. J. Podestá and A. J. Arvia, An. Asoc. Quim. Arg. 74, 65 (1986).

12. L. F. Spencer, Metal Finishing 10, 35 (1974).

13. W. J. Lorenz, I. Moumtzis and E. Schmidt, J. electroanal. Chem. 33, 121 (1971).

14. T. M. Riedhammer, L. S. Melnicki and S. Bruckenstein. Z. Phys. Chem. Neue Folge 111, 177 (1978).

15. L. Meites (Ed), Handbook of Analytical Chemistry, pp. 1-39. McGraw-Hill, New York (1963). 